\section{Safety in the Chemical Industry}

IN 1928, the council of the Association of British Chemical Manufacturers decided to prepare and issue to its members for their guidance a set of model safety rules for use in chemical works. These rules were based on the Factory and Workshop Act, the Chemical Works Regulations, the Electricity Regulations and similar statutory provisions, together with other precautions suggested from experience, and they represented the first attempt to draw up a comprehensive safety code for the chemical industry. The first part of the model rules, consisting of the proposed safety rules in concise form, was completed and issued in provisional form early in 1929. Various amendments and additions have been suggested in the light of the experience gained during the past nine years, and this part has now been issued in final form covering the provisions of the new Factories Act, 1937. It is in the nature of an introduction to Part 2, the first section of which was also issued in 1929, and it is hoped to revise and complete it also for issue at an early date. The model rules, Part 1, consist of eight sections, the first being a general section. The following sections deal with rules for the design and operation of plant with fire and explosive risks, for plant involving risks from gas, vapour, fume or dust, for plant involving dangers from contact with corrosive or deleterious substances and for plant involving other risks. The last three sections deal with fire protection, first aid, and with welfare. The publication is a part of the services provided for by the Association for its members, but so much importance is attached to dissemination of safety information that the Association is prepared to supply copies to firms outside its own membership on special request.

\section{Malaria-Therapy by Means of Infected Mosquitos}

Treatment of general paralysis of the insane by means of induced malaria, commenced in 1917, has been adopted everywhere. In the early days of malaria therapy, the fever was induced by the injection of the infected blood of a malaria patient, and this is still occasionally done; but generally the fever is now transmitted through the bites of infected mosquitos. This has been rendered possible by the establishment of a 'mosquito farm' at the Horton Mental Hospital. Full details respecting this 'mosquito farm', and of the methods employed for breeding, infecting and transmission are given in a recently issued report by Lieut.-Colonel J. A. Sinton ("A Report on the Provision and Distribution of Infective Material for the Practice of Malaria-Therapy in England and Wales". Reports on Pub. Health and Med. Subjects, No. 84. London : H.M. Stationery Office. $6 d$. net). At Horton, in a special insectary, an indigenous species of mosquito, Anopheles maculipennis, var. atroparvus, is bred throughout the year, freshly hatched females are collected and are stored in cages in an outhouse, being allowed to feed on a rabbit at appropriate intervals. When required for transmission work, the insects are placed in a special hot room for 48 hours, and are then allowed to feed upon a suitable patient with malaria in the wards of the hospital. A special Madagascar strain of benign tertian malaria parasite, $P$. vivax, is that used. A batch of 100-200 mosquitos are allowed to feed on the selected case, the insects being placed in jars and applied to the thigh of the patient. When most of the mosquitos seem to have fed, the jars are removed and the insects are then released into a storage cage, which is kept in a hot room maintained at about $75^{\circ} \mathrm{F}$., and are fed every second day on a rabbit. After 10 days or so, when parasites are found in the salivary glands of the insects, the mosquitos are ready for use for transmission; they remain active for about a month. For the transmission to a patient for the 'cure', about 15-20 infected insects are placed in jars, and are taken to the hospital where the patient is. The mosquitos are then given an opportunity of biting by applying the gauzecovered end of the feeding jar to the external surface of the patient's thigh.

\section{Mining and Fuel Technology at Sheffield}

The University of Sheffield's report on research work carried out in the Departments of Mining and Fuel Technology during the session 1936-37, recently published, gives a particularly lucid summary of progress made in the work undertaken by those two Departments. Within the confines of its twenty pages it is not possible to include a compre. hensive account of every phase of the research, nor to publish many of the valuable results obtained. Nevertheless it can be amplified by reference to the technical papers cited in the appendix or by direct appeal to the university authorities. The Department of Mining has been concerned chiefly with the problem of provision in advance of ventilating schemes for projected workings, and it is hoped to publish tables from which it will be possible to calculate roadway sizes required to provide adequate ventilation under varying conditions. Problems of deterioration in efficiency of high candle-power electric lamps, resistance of different types of trailing cables to mechanical damage, influence of design and material on chain coal-cutter picks and investigations into the nature and conditioning of washery water, have received careful consideration by the Department, and valuable data have been adduced in these connexions. The Department of Fuel Technology has been concerned during the period with the compilation of a revised method of classification of coal with the view of ultimate definition of the relationship between compositions and properties of different coals. This work has been facilitated by the discovery of differences in behaviour between the younger and older coals which afford a useful basis of classification of coals of varying geological age.

\section{Earthquake of August I6}

AN earthquake of 'destructive' intensity was recorded on seismographs in Great Britain in the early hours of Tuesday, August 16. The epicentre of the shock is calculated to be about 5,500 miles away, possibly in the plains of Central Asia. A message from the seismological station at Hamburg, 